\title{
Effect of salbutamol on dynamic hyperinflation in chronic obstructive pulmonary disease patients
}

\author{
C. Tantucci*, A. Duguet ${ }^{+}$, T. Similowski+, M. Zelter+, J-P. Derenne+ ${ }^{+}$J. Milic-Emili
}

Effect of salbutamol on dynamic hyperinflation in chronic obstructive pulmonary disease patients. C. Tantucci, A. Duguet, T. Similowski, M. Zelter, J-P. Derenne, J. Milic-Emili. (C)RS Journals Ltd 1998.

ABSTRACT: Expiratory flow limitation (EFL), which promotes dynamic hyperinflation and increased work of breathing, often occurs in chronic obstructive pulmonary disease (COPD). The purpose of this study was to assess the effect of bronchodilators on EFL and end-expiratory lung volume in patients with moderate-to-severe COPD.

EFL was assessed by applying negative expiratory pressure (NEP) at the mouth during tidal expiration. EFL was present when expiratory flow did not increase or increased only in the early phase of expiration with NEP. In 18 patients (age $65 \pm 2$ yrs; forced expiratory volume in one second $(\mathrm{FEV} 1)=45 \pm 4 \%$ predicted) pulmonary function tests and a series of NEP $\left(-3.5 \mathrm{cmH}_{2} \mathrm{O}\right)$ test breaths were performed at rest in a sitting position before and $20 \mathrm{~min}$ after inhalation of $400 \mu \mathrm{g}$ of salbutamol.

EFL was detected in 11 patients and persisted after salbutamol in all of these flow-limited (FL) patients. After bronchodilator administration FL patients exhibited a significant decrease in functional residual capacity (FRC) associated with an increase in inspiratory capacity (IC). In contrast, no changes in FRC and IC were observed in the seven non flow-limited (NFL) patients after administration of salbutamol. Except for one NFL patient, the other 17 patients (six NFL and 11 FL) had no reversibility of their bronchial obstruction $(\triangle \mathrm{FEV} 1<10 \%$ pred $)$

In conclusion, patients with chronic obstructive pulmonary disease and expiratory flow limitation, even if nonresponders in terms of forced expiratory volume in one second, may benefit from bronchodilators because they can breathe, still in a flowlimited manner, at a lower lung volume.

Eur Respir J 1998; 12: 799-804.
* Clinica di Semeiotica Medica, University of Ancona, Ancona, Italy. +Laboratoire de Physiopathologie Respiratoire du Service de Pneumologie et Service d'Exploration Fonctionnelle Respiratoire, Groupe Hospitalier Pitié-Salpêtrière, University of Paris VI, Paris, France. Meakins-Christie Laboratories, McGill University, Montreal, Québec, Canada.

Correspondence: C. Tantucci, Clinica di Semeiotica Medica, Universita di Ancona, Ospedale Regionale Torrette, 60020 Ancona, Italy

Fax: 3971883913

Keywords: Chronic airway obstruction, dynamic hyperinflation, negative expiratory pressure, pulmonary function tests, salbutamol

Received: October 201997

Accepted after revision June 261998

Supported by UPRES 2397 (M. Zelter, J-P. Derenne, T. Similowski) and in part by Glaxo-Wellcome, France. Presented as poster communication at the ATS International Conference, San Francisco, May 18-21, 1997.
Bronchodilating agents are commonly used in patients with chronic obstructive pulmonary disease (COPD) to reduce airway obstruction [1]. Although many COPD patients may obtain substantial increase in airflow after inhalation of bronchodilators [2], one-third of them do not show significant acute spirometric changes [3]. It is a common tenet, however, that improvements in symptoms and exercise capacity may occur even in the absence of spirometric improvement [4]. Such findings are frequent in patients with relatively severe COPD (forced expiratory volume in one second (FEV1) $<50 \%$ pred), who often exhibit expiratory flow limitation (EFL) during resting breathing, i.e. their tidal expiratory flow is maximal under the prevailing condition [5].

In the presence of EFL, the expiratory flow can increase only by breathing at higher lung volume. Thus, EFL promotes dynamic pulmonary hyperinflation, a condition where the end-expiratory lung volume (EELV) is greater than the relaxation or elastic equilibrium volume $(V r)$. As a result, there is a positive end-expiratory pressure (PEEP) in the alveoli which is called intrinsic PEEP (PEEPi) and acts as an inspiratory threshold load [6]. Dynamic hyperinflation is associated not only with increased inspiratory work due to PEEPi [7] but also with impaired inspiratory muscle function [8]. This, together with flow-limiting dynamic compression during tidal breathing, may contribute to dyspnoea in flow-limited COPD patients [9, 10]. Indeed, in a study by ELTAYARA et al. [9], the severity of chronic dyspnoea was found to correlate much more closely with flow limitation than with usual spirometric indices.

The aim of this study was to assess whether, in patients with moderate-to-severe COPD, the administration of a bronchodilator (short-acting $\beta_{2}$-agonist) abolished EFL and/or reduced the EELV during tidal breathing. EFL was assessed with the negative expiratory pressure (NEP) method $[5,11]$. Tidal EFL was also assessed with the conventional method based on comparison of tidal with maximal flow-volume $\left(V^{\prime}-V\right)$ curves obtained with body plethysmography [12].

\section{Methods}

\section{Subjects}

Eighteen patients (14 males and four females, aged $65 \pm 2$ yrs (mean \pm SEM), range 48-77 yrs) suffering from COPD according to the American Thoracic Society (ATS) guidelines [1] were studied when in a stable condition. 
The patients had airflow obstruction $(\mathrm{FEV} 1=1.19+0.12 \mathrm{~L}$; FEV1/forced vital capacity $(\mathrm{FVC})=42.2+2.7 \%)$ and no other respiratory or cardiac diseases. All were free from musculoskeletal disorders. None of the patients had received inhaled short-acting $\beta_{2}$-agonists or anticholinergics for $8 \mathrm{~h}$ before the study or long-acting $\beta_{2}$-agonists for $24 \mathrm{~h}$ before the study. None of the patients was receiving oral $\beta_{2}$-agonists, theophylline or systemic corticosteroids. None had had an upper respiratory tract infection in the previous 2 months. Each patient gave informed consent and the study protocol was approved by the local Ethics Committee.

\section{Study design}

The patients were investigated in the morning, in a sitting position before and $20 \mathrm{~min}$ after the administration of $400 \mu \mathrm{g}$ salbutamol through a metered-dose inhaler and an inhalation chamber. Both the dosage and the method of administration were chosen to maximize the effect of the drug. On each occasion, all patients underwent spirometric measurements by body plethysmography and application of NEP of $-3.5 \mathrm{cmH}_{2} \mathrm{O}$, which was administered at the beginning of tidal expiration and maintained throughout the ensuing expiration.

The severity of chronic dyspnoea was rated according to the modified Medical Research Council (MRC) dyspnoea scale [9] before the ventilatory and NEP tests.

\section{Measurements}

Spirometric measurements were performed using a constant volume/pressure body plethysmograph (Autobox 2800; Sensor Medics, Yorba Linda, CA, USA). Mouth and box flow were measured through a hot-wire pneumotachograph linear up to $14 \mathrm{~L} \cdot \mathrm{s}^{-1}$ (Sensor Medics). Volume was obtained by integrating the flow signal. The mouth flow signal was calibrated by a $3 \mathrm{~L}$ syringe and the box flow signal by using a sinusoidal signal generated by a 50 mL pump at $2 \mathrm{~Hz}$.

As soon as the subjects reached quiet, regular tidal breathing, the thoracic gas volume at end-tidal expiration (functional residual capacity (FRC)) was determined in duplicate by asking them to support their cheeks and pant at a frequency of $<1 \mathrm{~Hz}$ [13] against a closed shutter. The frequency response of the system was accurate up to 12 Hz. Immediately after the opening of the shutter, the subjects inspired slowly until maximum to obtain the inspiratory capacity (IC) and compute the total lung capacity $(\mathrm{TLC}=\mathrm{FRC}+\mathrm{IC})$, and then expired slowly and completely for the measurement of vital capacity (VC) and computation of residual volume (RV = TLC-VC). Afterwards, tidal and subsequent maximal full flow/volume curves were determined by plotting simultaneously the flow change at the mouth against the thoracic gas volume ( $V$ th) obtained by time-integration of the box flow ( $V^{\prime}-V$ th). In all instances the subjects inspired normally until TLC and then expired forcefully without an end-inspiratory pause to obtain the FVC.

For analysis the highest FEV1 and the forced expiratory manoeuvre with the largest sum of FEV1+FVC were selected from two acceptable expiratory manoeuvres, according to the ATS guidelines [14]. The tidal $V^{\prime}-V$ curve and maximal full $V^{\prime}-V$ th curve were superimposed on paper using a Hewlett-Packard 850C graphic-printer. The reference values used were those of the European Coal and Steel Community [15].

NEP measurements were carried out $10 \mathrm{~min}$ after spirometry under baseline conditions and before spirometry after administration of salbutamol for technical reasons. The experimental set-up used to assess EFL by NEP was similar to that described in detail previously [5]. All patients were studied seated upright in a comfortable chair while breathing through the equipment assembly with the noseclip on. The dead space of the equipment assembly was $<30 \mathrm{~mL}$ and its pressure-flow relationship was characterized by the following equation: $P=0.85 V^{\prime}+0.70 V^{\prime 2}$, where pressure $(P)$ is in $\mathrm{cmH}_{2} \mathrm{O}$ and $V^{\prime}$ in $\mathrm{L} \cdot \mathrm{s}^{-1}$.

During the NEP trials, flow $\left(V^{\prime}\right)$ was measured with a Hans-Rudolph pneumotachograph with a $\pm 2.6 \mathrm{~L} \cdot \mathrm{s}^{-1}$ linearity range (model 4700A; Hans-Rudolph, Kansas City, MO, USA) connected to the mouthpiece and a differential pressure transducer (MP45, $\pm 2 \mathrm{cmH}_{2} \mathrm{O}$; Validyne, Northridge, CA, USA). Pressure was measured at the mouth (Pmo) via a noncompliant polyethylene tube (ID=1.7 $\mathrm{mm})$ connected to a differential pressure transducer (DP15, \pm 150 $\mathrm{cmH}_{2} \mathrm{O}$; Validyne). The system used to measure $P$ mo had no appreciable shift or alteration in amplitude up to $20 \mathrm{~Hz}$.
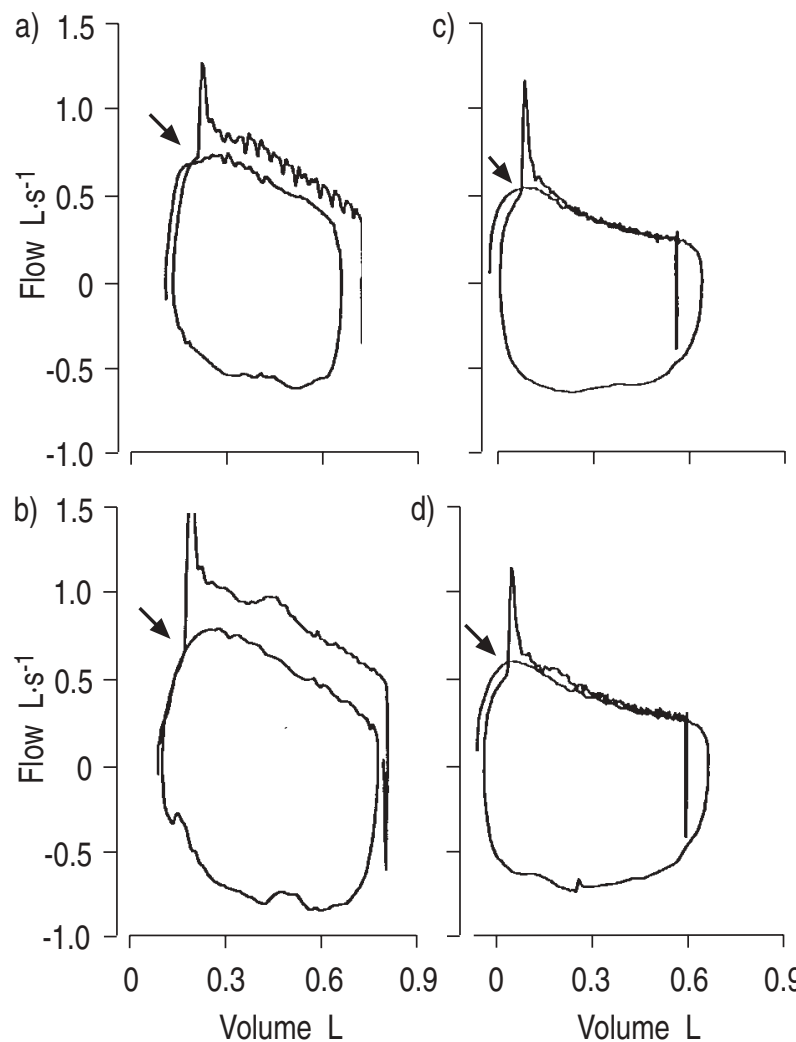

Fig. 1. - Examples of a nonflow-limited (NFL; a, b) and a flow-limited (FL; c, d) patient, before $(\mathrm{a}, \mathrm{c})$ and after $(\mathrm{b}, \mathrm{d})$ administration of the bronchodilator (BD). When expiratory flow with negative expiratory pressure (NEP; arrow) increases relative to control expiration, there is no expiratory flow limitation (NFL) $(a, b)$. In contrast, when the expiratory flow with NEP does not increase throughout the entire or part of the expiration compared with the flow of the preceding tidal expiration, there is expiratory flow limitation (EFL) (c, d). In this flow-limited patient, EFL persisted after BD. 
After about $30 \mathrm{~s}$ of regular breathing, several NEP tests were performed at intervals of six to eight breaths both under baseline conditions and after administration of salbutamol. The test breath was the breath during which NEP was applied during expiration, and the preceding expiration served as the control.

\section{Data analysis}

The patients were categorized as flow-limited (FL) and nonflow-limited (NFL) according to the results of the NEP tests. If under baseline conditions NEP elicited increased flow over the entire range of the control tidal volume $(V \mathrm{~T})$, the subject was NFL (fig. 1a). In contrast, if with NEP the subject exhaled even partly or entirely along the control $V^{\prime}-V$ curve, EFL was present (fig. 1c). The same approach was followed after administration of the bronchodilator (fig. 1b and d).

The patients were classified as responders and nonresponders to bronchodilator according to a change in FEV1 of more or less than $10 \%$ of the predicted value, i.e. (postFEV1-preFEV1)/predFEV1 $\times 100$ ) [16], respectively, as recommended by the European Respiratory Society (ERS) consensus statement [17]. Although the ATS criteria indicate a $12 \%$ change of baseline FEV1 and an absolute increase of $200 \mathrm{~mL}$ as significant response to a bronchodilator [14], $\triangle \mathrm{FEV} 1$ as per cent of predicted value is less significantly correlated to the initial FEV 1 and, thus, does not give an unjustified advantage to low baseline values of FEV1 [18-20], being more appropriate on a single crosssectional assessment of reversibility of the bronchial obstruction in COPD patients [21, 22].

\section{Statistical analysis}

Descriptive group data were compared using Student's statistics. Regression relationships were established using the least squares method. Data are expressed as mean \pm SEM. A p-value $<0.05$ was considered significant.

Table 1. - Anthropometric and functional characteristics of the patients

\begin{tabular}{lccc}
\hline & NFL & FL & p-value \\
\hline Subject n & 7 & 11 & \\
Sex M/F & $6 / 1$ & $8 / 3$ & \\
Age yrs & $64 \pm 3$ & $66 \pm 3$ & Ns \\
Height cm & $171 \pm 5$ & $163 \pm 2$ & $<0.05$ \\
Weight kg & $71 \pm 5$ & $66 \pm 5$ & Ns \\
Dyspnoea MRC scale & $1.8 \pm 0.2$ & $3.0 \pm 0.2$ & $<0.01$ \\
$P \mathrm{a}, \mathrm{O}_{2}$ mmHg & $74 \pm 3$ & $68 \pm 3$ & Ns \\
$P \mathrm{a}, \mathrm{CO}_{2} \mathrm{mmHg}$ & $41 \pm 1$ & $47 \pm 2$ & $<0.05$ \\
$\mathrm{TLC} \%$ pred & $104 \pm 6$ & $119 \pm 6$ & Ns \\
VC \% pred & $87 \pm 4$ & $78 \pm 6$ & Ns \\
FRC \% pred & $128 \pm 12$ & $162 \pm 13$ & Ns \\
FEV1 \% pred & $54 \pm 3$ & $40 \pm 6$ & NS \\
FVC \% pred & $85 \pm 4$ & $78 \pm 7$ & NS \\
FEV1/FVC \% & $48 \pm 2$ & $39 \pm 4$ & Ns \\
\hline
\end{tabular}

Data are mean \pm SEM. NFL: nonflow-limited; FL: flow-limited, according to negative expiratory pressure method; $P \mathrm{a}, \mathrm{O}_{2}$ : arterial oxygen tension; $P \mathrm{a}, \mathrm{CO}_{2}$ : arterial carbon dioxide tension; TLC: total lung capacity; VC: vital capacity; FRC: functional residual capacity; FEV1: forced expiratory volume in one second; FVC: forced vital capacity; M: male; F: female; ns: nonsignificant. $1 \mathrm{mmHg}=0.133 \mathrm{kPa}$.

\section{Results}

Under baseline conditions, EFL was detected in 11 COPD patients according to the NEP method. In all instances the results were reproducible in the repeated NEP tests. The anthropometric and functional characteristics of FL and NFL patients are shown in table 1. The FL patients were characterized by more severe chronic dyspnoea (MRC scale) and abnormal arterial carbon dioxide tension $\left(P \mathrm{a}, \mathrm{CO}_{2}\right)$. The FL patients had higher FRC ( $\mathrm{p}=0.09$, nonsignificant (Ns)) and lower FEV 1 (p=0.06, NS) than the NFL patients, indicating greater pulmonary hyperinflation and airway obstruction.

In none of the 11 COPD patients who were FL under baseline conditions, did EFL disappear following the administration of salbutamol.

Only one of the 18 COPD patients, who was NFL under baseline conditions, had a $\triangle \mathrm{FEV} 1>10 \%$ pred after salbutamol (fig. 2a).

In both NFL and FL subgroups of COPD patients, TLC measured after salbutamol did not change significantly, decreasing by $2.4 \pm 0.5 \%(6.66 \pm 0.35$ versus $6.50 \pm 0.33 \mathrm{~L})$
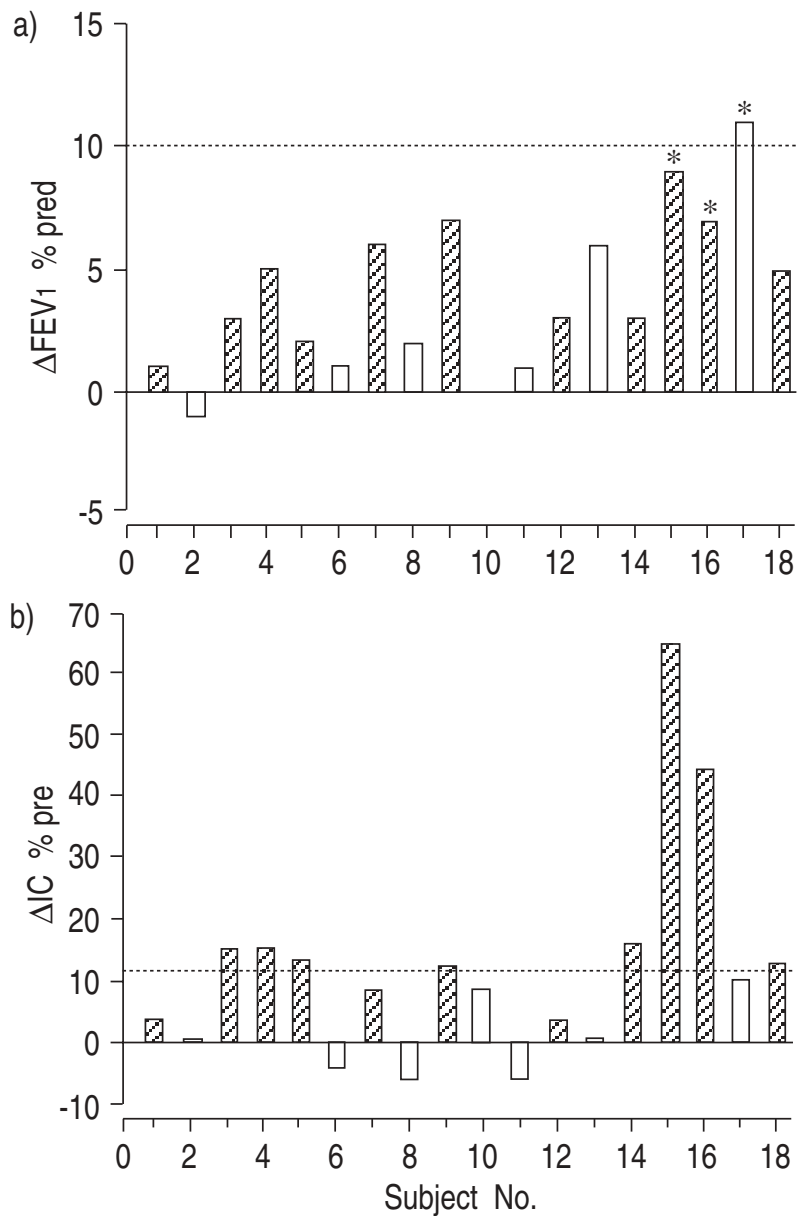

Fig. 2. - a) Changes in forced expiratory volume in one second $\left(\triangle \mathrm{FEV}_{1}\right)$ and $\left.\mathrm{b}\right)$ inspiratory capacity $(\Delta \mathrm{IC})$ after salbutamol in $11 \mathrm{mod}$ erate-to-severe patients with chronic obstructive pulmonary disease who were flow-limited (FL; ) ands seven who were nonflow-limited (NFL; ) underbaseline conditions. $\quad$ inctrcates in a) an FEV 1 increase of $10 \%$ relative to predicted value (\% pred), and in b) an IC increase of $12 \%$ relative to baseline ( $\%$ pre). $*$ : indicate the subjects with $\triangle \mathrm{FEV} 1$ $>12 \%$ of baseline and an absolute increase in FEV $1>200 \mathrm{~mL}$. 


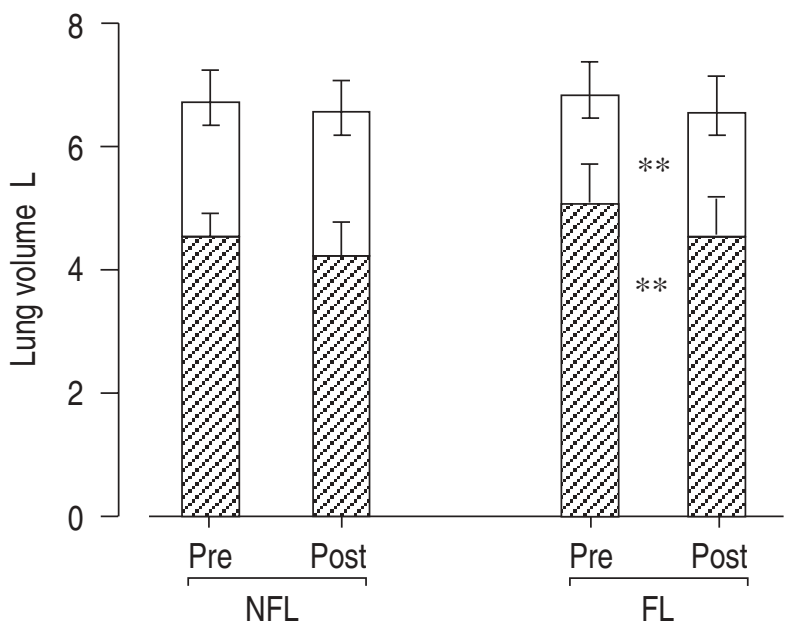

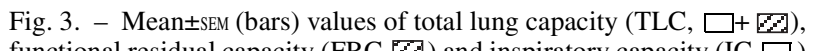
functional residual capacity (FRC, $Q 2$ ) and inspiratory capacity (IC, $\square$ ) in nonflow-limited (NFL; $n=7)$ and flow-limited ( $F L ; n=11)$ patients with chronic obstructive pulmonary disease before (pre) and after (post) administration of the bronchodilator. While TLC remained essentially unchanged, the FRC decreased and IC increased significantly in the FL subgroup. ${ }^{*}: \mathrm{p}<0.01$ pre versus post.

and $3.5 \pm 1.5 \%(6.70 \pm 0.41$ versus $6.45 \pm 0.33 \mathrm{~L})$, respectively, compared with baseline (fig. 3). In the FL subgroup this was associated with a significant $(\mathrm{p}<0.01)$ increase in IC (from $1.68 \pm 0.16$ to $1.98 \pm 0.20 \mathrm{~L}$ ) and decrease in FRC (from $5.03 \pm 0.44$ to $4.53 \pm 0.40 \mathrm{~L}$ ). In the NFL subgroup there was no change in IC $(2.33 \pm 0.21$ versus $2.33 \pm 0.18 \mathrm{~L})$ or FRC (4.34 \pm 0.42 versus $4.20 \pm 0.36 \mathrm{~L})$ (fig. 3). In eight FL patients the increase in IC $(\Delta \mathrm{IC})$ after salbutamol was greater than $12 \%$ with respect to the control value (fig. 2b). A significant positive correlation between the changes in IC and those in FEV1 was found after bronchodilator only in the FL patients $(r=0.86, p<0.001)$.

The breathing pattern data are shown in table 2 . Under baseline conditions only inspiratory time $(t \mathrm{I}) /$ duration of total breathing cycle (ttot) was significantly different between NFL and FL patients, being lower in FL patients. After salbutamol, the FL patients exhibited a significant increase in minute ventilation $\left(V^{\prime} \mathrm{E}\right)$ and mean expiratory

Table 2. - Breathing pattern data before and after bronchodilator

\begin{tabular}{|c|c|c|c|c|}
\hline & \multicolumn{2}{|c|}{ NFL } & \multicolumn{2}{|c|}{ FL } \\
\hline & Before BD & After BD & Before BD & After BD \\
\hline$V$ T $\mathrm{L}$ & $0.75 \pm 0.07$ & $0.79 \pm 0.08$ & $0.74 \pm 0.09$ & $0.77 \pm 0.10$ \\
\hline$f \mathrm{R}$ breaths $\cdot \min ^{-1}$ & $19.4 \pm 1.9$ & $19.4 \pm 1.8$ & $17.2 \pm 1.4$ & $19.2 \pm 2.0$ \\
\hline$V^{\prime} \mathrm{E} L \cdot \min ^{-1}$ & $13.8 \pm 0.4$ & $14.5 \pm 0.6$ & $12.0 \pm 0.9$ & $13.7 \pm 1.2 *$ \\
\hline$t \mathrm{I} \mathrm{S}$ & $1.26 \pm 0.15$ & $1.25 \pm 0.15$ & $1.23 \pm 0.09$ & $1.17 \pm 0.07$ \\
\hline$t \mathrm{E} \mathrm{s}$ & $2.06 \pm 0.21$ & $2.06 \pm 0.20$ & $2.53 \pm 0.22$ & $2.32 \pm 0.29$ \\
\hline$t \mathrm{I} / t \mathrm{tot}$ & $0.38 \pm 0.01$ & $0.37 \pm 0.02$ & $0.33 \pm 0.01^{\dagger}$ & $0.35 \pm 0.02$ \\
\hline$V \mathrm{~T} / t \mathrm{I} \mathrm{L} \cdot \mathrm{s}^{-1}$ & $0.60 \pm 0.02$ & $0.64 \pm 0.02$ & $0.60 \pm 0.04$ & $0.65 \pm 0.06$ \\
\hline$V \mathrm{~T} / t \mathrm{E} \quad \mathrm{L} \cdot \mathrm{s}^{-1}$ & $0.37 \pm 0.02$ & $0.39 \pm 0.02$ & $0.30 \pm 0.03$ & $0.35 \pm 0.04$ \\
\hline
\end{tabular}

Data are mean+sEM. NFL: nonflow-limited; FL: flow-limited, according to negative expiratory pressure method; BD: bronchodilator (salbutamol); $V \mathrm{~T}$ : tidal volume; $f \mathrm{R}$ : respiratory frequency; $V^{\prime} \mathrm{E}$ : minute ventilation; $t \mathrm{I}$ : inspiratory time; $t \mathrm{E}$ : expiratory time; $t$ tot: duration of total breathing cycle; $V \mathrm{~T} / t \mathrm{t}$ : mean inspiratory flow; $V \mathrm{~T} / t \mathrm{E}$ : mean expiratory flow. $t \mathrm{p}<0.05$, NFL versus $\mathrm{FL}$; *: $\mathrm{p}<0.05$, before versus after BD. flow ( $V \mathrm{~T} /$ expiratory time $(t \mathrm{E}))$, whilst no such differences were found in the NFL patients.

In all COPD patients a negative correlation was observed between the degree of chronic dyspnoea and the baseline absolute value of IC $(r=0.65 ; p<0.05)$.

When EFL was assessed with the conventional method using the body plethysmograph, 13 COPD patients were considered as FL. After bronchodilator, four of these FL patients became NFL, as inferred from the comparison of tidal with maximal expiratory $V^{\prime}-V$ th curves.

\section{Discussion}

The results of this study indicate that in FL patients with moderate-to-severe COPD, tidal EFL persisted after administration of the bronchodilator. Nevertheless, most of the FL patients exhibited a significant decrease in FRC associated with an increase in IC, reflecting a reduction in dynamic pulmonary hyperinflation.

\section{Assessment of expiratory flow limitation by conventional method}

It is common practice to infer EFL from the relationship between tidal and maximal expiratory $V^{\prime}-V$ curves, as first suggested by Hyatт [12]. This method, which requires a voluntary effort as well as co-operation and coordination from the patient, is affected by the volumedependent changes in airway resistance and lung recoil during full inspiration before the FVC manoeuvre [23]. It is also affected by the time-dependent viscoelastic behaviour of thoracic tissues and time-dependent lung emptying due to time constant inequality [24, 25]. Since the previous volume and time history varies between tidal and full inspiration, it follows that this method may lead to erroneous conclusions, even when volume is measured with a body plethysmograph to avoid thoracic gas compression artefacts [26, 27].

In contrast, the NEP method requires neither collaboration from the patient nor the use of a body plethysmograph to avoid errors due to thoracic gas compression. Moreover, since the control and the NEP test breaths have similar lung volume and time history, the NEP method appears more reliable to assess tidal EFL correctly [5].

This explains the discrepancy observed in the detection of EFL between the NEP and conventional method in these COPD patients. Under baseline conditions two patients would have been erroneously classified as FL on the basis of the conventional method. After salbutamol, erroneous assessment of EFL was made in six patients. These findings indicate that the effect of bronchodilation on EFL cannot be assessed by a comparison of tidal with maximal $V^{\prime}-V$ curves, as shown previously [26].

In eight FL COPD patients the increase in IC was Š $12 \%$, although none of them responded to salbutamol $(\triangle \mathrm{FEV} 1<10 \%$ pred). It should be noted, however, that there was a significant $(\mathrm{p}<0.001)$ correlation between the changes in IC and FEV1 due to salbutamol and that two FL patients (numbers 15 and 16) would have been classified as responders according to the ATS criteria.

These data suggest that measurements of lung volume, in particular IC, should be performed after bronchodilator 
in COPD with EFL. Indeed, a substantial increase in IC should represent a meaningful indication to prescribe bronchodilating drugs even if the changes in FEV 1 do not satisfy the criteria of reversibility.

Figure 4 shows this effect in patient number 15 . The tidal $V^{\prime}-V$ loops, before and after salbutamol, are aligned with absolute lung volume together with the corresponding maximal expiratory $V^{\prime}-V$ curves obtained by extrapolation of the tidal $V^{\prime}-V$ curves. In both instances, the application of NEP did not increase the expiratory flow, indicating EFL. After bronchodilator, however, tidal breathing started at a markedly lower EELV. This demonstrates that after bronchodilators, dynamic pulmonary hyperinflation can decrease substantially in FL COPD patients. Such behaviour was observed in another seven FL patients.

The fact that three FL patients (numbers 1, 7 and 12) exhibited only a small increase of IC after bronchodilator could reflect either a poor bronchodilating effect, as in patients number 1 and 12 (fig. 2) or increased expiratory flow due to a change in breathing pattern following salbutamol. This was the case for patient number 7, who increased the mean expiratory flow from $0.34 \pm 0.02$ to $0.50 \pm$ $0.01 \mathrm{~L} \cdot \mathrm{s}^{-1}$.

In contrast to supine asthmatics [26] and mild COPD patients [28], in the present subjects with moderateto-severe COPD, EFL was not reversed after administration of the bronchodilator. However, in the study by PELLEGRINO and BRUSASCO [28] in COPD patients, EFL was detected by comparing tidal expiratory flow with flow obtained during a subsequent submaximal tidal expiration, a questionable method by which to assess EFL, as discussed before, and gives results not fully comparable with those obtained by the NEP technique.

In the present NFL patients there were no significant changes in FRC and IC after bronchodilator, independ-

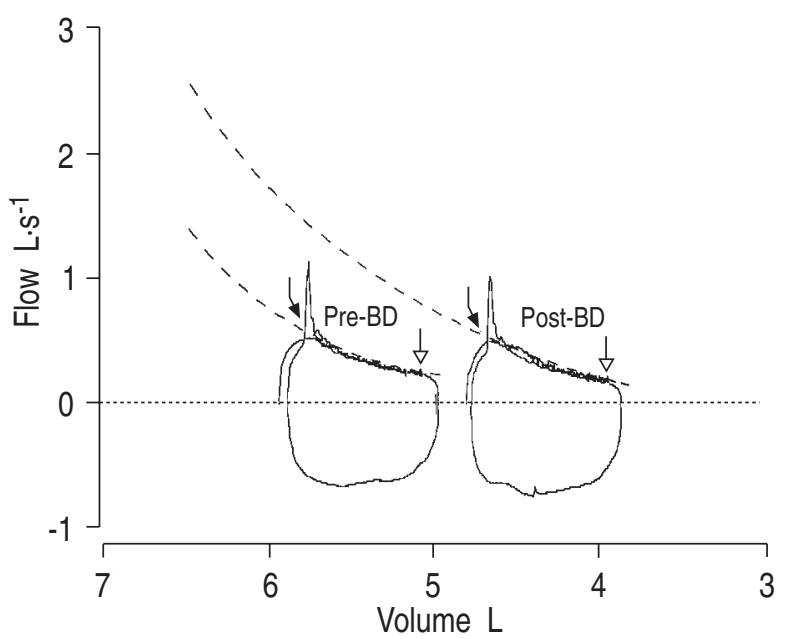

Fig. 4. - Tidal flow-volume ( $\left.V^{\prime}-V\right)$ loops immediately before and during application of negative expiratory pressure (NEP) are displayed together with the corresponding extrapolated maximal expiratory $V^{\prime}-V$ curves in a representative flow-limited chronic obstructive pulmonary disease patient (number 15; forced expiratory volume in one second $\left(F_{1}\right)=24 \%$ predicted) before (pre) and after (post) administration of the bronchodilator $(\mathrm{BD})$. Pre-BD: functional residual capacity $(\mathrm{FRC})=$ $4.99 \mathrm{~L}$; inspiratory capacity $(\mathrm{IC})=1.69 \mathrm{~L} ; \mathrm{FEV}_{1}=0.70 \mathrm{~L}$. Post-BD: FRC $=$ $3.90 \mathrm{~L} ; \mathrm{IC}=2.76 \mathrm{~L} ; \mathrm{FEV}_{1}=0.99 \mathrm{~L} . \mathbf{\downarrow}$ : application; $\boldsymbol{\nabla}$ : removal of NEP. ently of $\triangle F E V_{1}$ (figs. 2 and 3). Since the TLC remained essentially unchanged after salbutamol, the lack of a decrease in FRC in the NFL patients suggests that their EELV was not dynamically regulated and corresponded to the relaxation volume of the respiratory system.

The occurrence or increase in dynamic pulmonary hyperinflation during physical exertion represents an important source of exertional breathlessness in COPD patients [29]. In FL COPD patients the EELV is often dynamically determined and markedly affected by the changes in breathing pattern during exercise. Regardless of the causal mechanism, it is obvious that while dynamic hyperinflation provides higher expiratory flows to meet the ventilatory requirements during exercise or even at rest, it does so only at the expense of disadvantageous mechanical consequences and unpleasant sensations [30]. Thus, in FL COPD patients a reduction in dynamic hyperinflation, which by definition is associated with increased IC, should represent a benefit. Apart from the mechanical advantage for the inspiratory muscles due to reduced dynamic hyperinflation after bronchodilator, a greater IC due to a decreased EELV allows larger tidal volumes to be achieved during exercise [29], resulting in increased exercise tolerance and decreased dyspnoea for a given task. The inverse relationship between the severity of chronic dyspnoea and the baseline IC suggests that a reduced inspiratory reserve, which is associated with pulmonary hyperinflation and a blunted response of $V \mathrm{~T}$ to exercise, contributes to the breathlessness experienced by these patients during daily activities. In this respect, it is worth noting that in the present COPD patients those with EFL exhibited more severe dyspnoea and, in general, smaller inspiratory reserve, reflecting a greater pulmonary hyperinflation. In two FL patients, however, IC was not reduced markedly, indicating that in some patients EFL at rest may not be associated with appreciable dynamic pulmonary hyperinflation.

In conclusion, the present study was undertaken to assess whether in patients with chronic obstructive pulmonary disease, bronchodilator administration can reverse tidal expiratory flow limitation if present, and reduce the degree of the concomitant dynamic hyperinflation. While all 11 patients with chronic obstructive pulmonary disease who were flow-limited before bronchodilator administration remained flow-limited after its administration, there was a significant decrease in functional residual capacity and an increase in inspiratory capacity, reflecting a reduction in the degree of dynamic hyperinflation. In contrast, in the seven nonflow-limited patients there were no significant changes in functional residual capacity or inspiratory capacity after bronchodilator administration, reflecting the fact that in these patients the functional residual capacity corresponded to the relaxation volume of the respiratory system. In short, in flow-limited patients with chronic obstructive pulmonary disease the benefit of bronchodilator therapy can be easily and meaningfully assessed in terms of changes in inspiratory capacity.

\footnotetext{
Acknowledgements: The authors thank P. Vallée for invaluable technical assistance and the staff at the Service d'Exploration Fonctionnelle Respiratoire, Groupe Hospitalier Pitié-Salpêtrière, for help in studying the patients under their care.
} 


\section{References}

1. American Thoracic Society. Standards for the diagnosis and care of patients with chronic obstructive pulmonary disease (COPD) and asthma. Am Rev Respir Dis 1987; 136: 225-244.

2. Filuk RB, Easton PA, Anthonisen NR. Response to large dose of salbutamol and theophylline in patients with chronic obstructive pulmonary disease. Am Rev Respir Dis 1985; 132: 871-874.

3. Nisar M, Harris JE, Pearson MG, Calverley PMA. Acute bronchodilator trials in chronic obstructive pulmonary disease. Am Rev Respir Dis 1992; 146: 555-559.

4. Guyatt GH, Townsend M, Pugsley SO, et al. Bronchodilators in chronic air-flow limitation. Effects on airway function, exercise capacity, and quality of life. Am Rev Respir Dis 1987; 135: 1069-1074.

5. Koulouris NG, Valta P, Lavoie A, et al. A simple method to detect expiratory flow limitation during spontaneous breathing. Eur Respir J 1995; 8: 306-313.

6. Pepe AE, Marini JJ. Occult positive end-expiratory pressure in mechanically ventilated patients with airflow obstruction: the auto-PEEP effect. Am Rev Respir Dis 1982; 26: 166-170.

7. Coussa ML, Guérin C, Eissa NT, et al. Partitioning of work of breathing in mechanically ventilated COPD patients. J Appl Physiol 1993; 75: 1711-1719.

8. Bellemare F, Grassino A. Force reserve of the diaphragm in patients with chronic obstructive pulmonary disease. $J$ Appl Physiol 1983; 55: 8-15.

9. Eltayara L, Becklake MR, Volta CA, Milic-Emili J. Relationship between chronic dyspnea and expiratory flow limitation in patients with chronic obstructive pulmonary disease. Am J Respir Crit Care Med 1996; 154: 17261734.

10. O'Donnell DE, Sani R, Anthonisen NR, Younes M. Effect of dynamic airway compression on breathing pattern and respiratory sensation in severe chronic obstructive pulmonary disease. Am Rev Respir Dis 1987; 135: 912-918.

11. Valta P, Corbeil C, Lavoie A, et al. Detection of expiratory flow limitation during mechanical ventilation. Am J Respir Crit Care Med 1994; 150: 1311-1317.

12. Hyatt RE. The interrelationship of pressure, flow and volume during various respiratory maneuvres in normal and emphysematous patients. Am Rev Respir Dis 1961; 83: 676-683.

13. Shore SA, Huk O, Mannix S, Martin JG. Effect of panting frequency on the plethysmographic determination of thoracic gas volume in chronic obstructive pulmonary disease. Am Rev Respir Dis 1983; 128: 54-59.

14. ATS. Lung function testing: selection of reference values and interpretative strategies. Am Rev Respir Dis 1991; 144: 1202-1218.

15. Quanjer PhH, Tammelin GJ, Cotes JE, Pedersen OF, Peslin R, Yernault J-C. Lung volumes and forced ventilatory flows. Report Working Party "Standardization of Lung
Function Tests". European Coal and Steel Community. Eur Respir J 1993; 6: Suppl. 16, 5-40.

16. Eliasson O, Degraff AC. The use of criteria for reversibility and obstruction to define patient groups for bronchodilator trials. Am Rev Respir Dis 1985; 132: 858-864.

17. Siafakas NM, Vermeire P, Pride NB, et al. Optimal assessment and management of chronic obstructive pulmonary disease (COPD). Eur Respir J 1995; 8: 13981420.

18. Anthonisen NR, Wright EC, IPPB Trial Group. Bronchodilator response in chronic obstructive pulmonary disease. Am Rev Respir Dis 1986; 133: 814-819.

19. Dompeling E, van Schayck CP, Molema J, et al. A comparison of six different ways of expressing the bronchodilating response in asthma and COPD; reproducibility and dependence of prebronchodilator FEV1. Eur Respir $J$ 1992; 5: 975-981.

20. Harf A. How to express the reversibility of bronchial obstruction? Eur Respir J 1992; 5: 919-920.

21. Dales RE, Spitzer WO, Tousignant P, Schechter M, Suissa S. Clinical interpretation of airway response to a bronchodilator. Epidemiologic considerations. Am Rev Respir Dis 1988; 138: 317-320.

22. Weir DC, Burge PS. Measures of reversibility in response to bronchodilators in chronic airflow obstruction: relation to airway caliber. Thorax 1991; 46: 43-45.

23. Mead J, Turner JM, Macklem PT, Little JB. Significance of the relationship between lung elastic recoil and maximum expiratory flow. J Appl Physiol 1967; 22: 95-108.

24. Melissinos CG, Webster P, Tien YK, Mead J. Time dependence of maximum flow as an index of nonuniform emptying. J Appl Physiol 1979; 47: 1043-1050.

25. D'Angelo E, Prandi E, Marazzini L, Milic-Emili J. Dependence of maximal flow- volume curve on timecourse of preceding inspiration in patients with chronic obstructive pulmonary disease. Am J Respir Crit Care Med 1994; 150: 1581- 1586.

26. Boczkowski J, Murciano D, Pichot M-H, Ferretti A, Pariente R, Milic-Emili J. Expiratory flow limitation in stable asthmatic patients during resting breathing. Am J Respir Crit Care Med 1997; 156: 752-757.

27. Murciano D, Pichot M-H, Boczkowski J, Sleiman C, Pariente R, Milic-Emili J. Expiratory flow limitation in COPD patients after single lung transplantation. Am $J$ Respir Crit Care Med 1997; 155: 1036-1041.

28. Pellegrino R, Brusasco V. Lung hyperinflation and flow limitation in chronic airway obstruction. Eur Respir $J$ 1997; 10: 543-549.

29. O'Donnell DE, Webb KA. Exertional breathlessness in patients with chronic airflow limitation. The role of lung hyperinflation. Am J Respir Crit Care Med 1993; 148: 1351-1357.

30. O'Donnell DE. Breathlessness in patients with chronic airflow limitation. Mechanisms and management. Chest 1994; 106: 904-912. 